\title{
Numerical study of thermal stresses for the semiconductor CdZnTe in vertical Bridgman
}

\author{
Hanen Jamai, ${ }^{1},{ }^{*}$, M. El Ganaoui ${ }^{2}$, Habib Sammouda ${ }^{1}$, Bernard Pateyron ${ }^{2}$ \\ ${ }^{1}$ LabEM (LR11ES34), University of Sousse, ESSTH Sousse, Rue Lamine Abbassi 4011 \\ Hammam Sousse, Tunisia \\ ${ }^{2}$ Université de Lorraine, Lab. Energétique de Longwy LERMAB/FJV 3 CNRS-SPCTS/CEC 12, \\ Rue Atlantis, 87068, Limoges \\ E-mail address: hanene_jamai@yahoo.fr
}

Keywords: thermal stress, solidification of CdZnTe, Bridgman Vertical, finite elements method

\begin{abstract}
The aim of this work is to present a numerical simulation of thermal stress in directional solidification of $\mathrm{CdZnTe}$ in vertical Bridgman apparatus. Especial attention will be attributed to show the importance of cooling temperature and time's growth affecting the thermal stress. Furthermore, we will focus on investigating the thermal stress' components and their distribution in crystal, which gives a detailed about the stress distribution and consequently on the distribution of defects during solidification of $\mathrm{CdZnTe}$
\end{abstract}

\section{INTRODUCTION}

The vertical Bridgman method for crystal growth from the melt was firstly developed in 1925. Nowadays, it is the most useful technique for the growth of crystals. This technique is explained at Figure. 1(a) Its perfections to control temperature gradients and to provide pure crystals of large sizes by allowing testing the boundary conditions of mass and heat transfer. Hence, such technique is widely utilized in order to produce II-VI compound semiconductor crystals.

Among these semiconductors, the Cadmium zinc telluride (CdZnTe) is considered as one of the most important and promising applied materials for room-temperature $\gamma$ and $X$ ray spectroscopy[1,2]. Despite the fact that great efforts have been made to produce high quality of CdZnTe dominated by the Bridgman method, its production still suffers from small device size and low quality. Nevertheless, and since 10 years ago, CdZnTe has found its application primarily in the process of development of highest performance infrared detectors based on HgCdTe [3]. It has become a leading substrate material for epitaxial growth of $\mathrm{HgCdTe}$ thin films for two main reasons. On the one hand, it is transparent in the infrared wavelength range, which allows back side illumination of detectors arrays connected to silicon read-out device by indium bump technology [4]. On the other hand, the addition of 3-5\% of zinc into CdTe leads to better lattice matching between the substrate and $\mathrm{HgCdTe}$ layer and significantly decreases the dislocation density of the crystals due to the $\mathrm{Cd}-\mathrm{Te}$ bond reinforcement [5].

CdZnTe and CdTe detectors are also suitable for the development of portable systems for mammographic X-ray spectroscopy [6-9]. However, The CdZnTe crystal suffers many defects, such as dislocation, striation, and impurities that significantly affect the final crystal quality. In fact, the generation of dislocation is related to thermal stresses induced by the inhomogeneous temperature distribution [10].

A numerical simulation was carried out by Huang et al [11] to study thermal stress. The authors showed that the axial temperature gradient is the main factor affecting the thermal stress $[11,12]$.

Chao et al [13] studied the temperature and stress fields for crystal growth in a vertical Bridgman furnace using the finite difference method. In fact they investigated the influence of the ratio of solid to liquid thermal conductivity and the transient effect. The others concluded that, a flat 
interface can decrease the thermal stresses induced by the radial temperature gradient, but a large temperature gradient in the axial direction within the crystal might result in large thermal stresses. And a smaller thermal stresses can be achieved by reducing both the radial and the axial temperature gradients. Rosch et al [14] investigated the interaction of the ampoule and GaAs crystal in a vertical Bridgman furnace. Their study proved that sticking is the primary cause of excess stress, but it can be reduced by matching the thermal expansion coefficient of the ampoule to the crystal.

Attention will be attributed to investigate the Von Mises stress which presents a principal parameter on thermal stress' study. We will focus on the various parameters such Time's growth and the cold temperature variation that affect the thermal stress in solidification process.

\section{MATERIALS AND METHODS}

The Bridgman crystal system is schematically displayed in figure. 1(a) The ampoule is axially positioned at the center of the growth furnace. During the process, the cylindrical ampoule containing the material in the solid and liquid phase is fixed at the constant rate $\mathrm{Vt}=0 \mathrm{~m} / \mathrm{s}$. Due to the symmetry of the system, the right half of figure. 1(c) is taken as the calculation domain is considered.

The furnace uses a tapered heating element to establish a linear temperature profile Figure. 1(d) along the outer surface ampoule plotted as a function of dimensionless distance along the furnace axis, where $\mathrm{z}=-0.01$ denotes the bottom tip of the ampoule and $\mathrm{z}=0.2$ corresponds to the ampoule height Figure 1(b). This thermal profile is based on two linear segments designed to yield a gradient in the melt and a steeper cooling rate in the crystal [15-18].

The physical properties of CdZnTe and the property of Ampoule are listed in Table 1 and in Table 2 respectively. It should be noted that these properties depend on the given temperature, and they are in accordance with the thermal boundary conditions, for each domains.

In the present study, the physical problem is assumed to be considered as a two dimensional axis-symmetry one, the temperature field, the Stefan equations and the thermal stress are expressed in the cylindrical coordinates system. There is only heat conduction between the melt and crystal. 


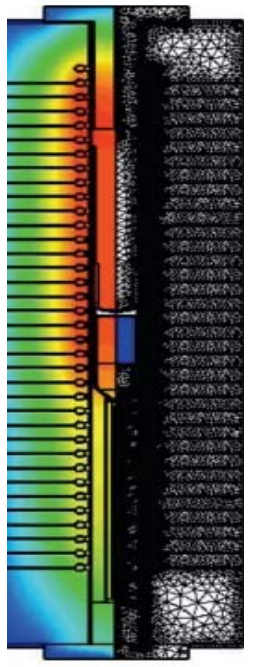

(a)Vertical Bridgman

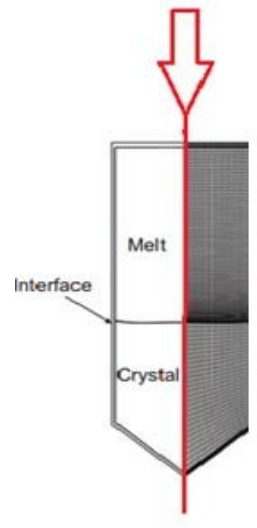

(b) Ampoule

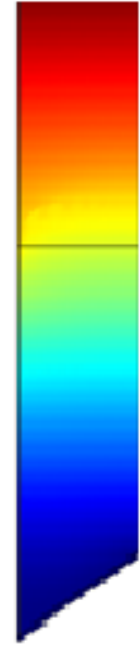

(c) Design domain

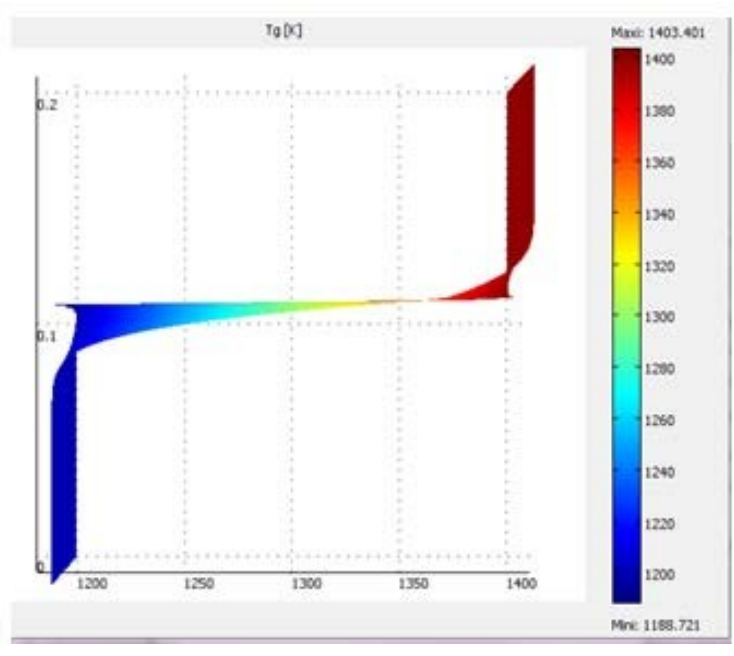

Isotherms profile (d)

Figure.1. System

Table 1: Physical properties of the CdZnTe [19, 20]

\begin{tabular}{|c|c|c|}
\hline property & temperature & polynomial \\
\hline Conductivity, W/ (K. m) & $\begin{array}{c}500 \mathrm{~K}<\mathrm{T}<1200 \mathrm{~K} \\
1200 \mathrm{~K}<\mathrm{T}<1364 \mathrm{~K} \\
\mathrm{~T}>1364 \mathrm{~K}\end{array}$ & $\begin{array}{c}5.337-2.263 .10^{-3} \mathrm{~T} \\
-38.31+6.7810^{-2} \mathrm{~T}-2.81110^{-5} \mathrm{~T}^{2} \\
9.987-5.67610^{-3} \mathrm{~T}\end{array}$ \\
\hline $\begin{array}{c}\text { Specific heat Cp, } \\
\text { J/(Kg.K) }\end{array}$ & $298 \mathrm{~K}<\mathrm{T}<1600 \mathrm{~K}$ & $177.8+1.66310^{-1} \mathrm{~T}-6.60710^{-5} \mathrm{~T}^{2}+1.70310^{-8} \mathrm{~T}^{3}$ \\
\hline Heat of fusion $\Delta \mathrm{H}, \mathrm{J} / \mathrm{Kg}$ & 209000 & 209000 \\
\hline Expansion coefficient & $\mathrm{T}>525 \mathrm{~K}$ & $6.362910^{-6}$ \\
\hline Melting point $\mathbf{T m}, \mathrm{K}$ & 1364 & - \\
\hline Density $\mathrm{Kg} / \mathrm{m}^{3}$ & - & 5680 \\
\hline
\end{tabular}

Physical properties of ampoule [19, 20]

\begin{tabular}{|c|c|c|}
\hline property & temperature & polynomial \\
\hline $\begin{array}{c}\text { Conductivity, Kq W/ } \\
\text { (K. m) }\end{array}$ & $298 \mathrm{~K}<\mathrm{T}<1600 \mathrm{~K}$ & $1.25+1.05 .10^{-3} \mathrm{~T}-3.9510^{-7} \mathrm{~T}^{2}+7.3310^{-11} \mathrm{~T}^{3}$ \\
\hline $\begin{array}{l}\text { Specific heat Cp, } \\
\text { J/(Kg.K) }\end{array}$ & $298 \mathrm{~K}<\mathrm{T}<1600 \mathrm{~K}$ & $760+0.634 \mathrm{~T}-2.3910^{-4} \mathrm{~T}^{2}+4.4410^{-8} \mathrm{~T}^{3}$ \\
\hline Density $\mathrm{Kg} / \mathrm{m}^{3}$ & - & 2200 \\
\hline Expansion coefficient & $\begin{array}{l}\mathrm{T}<1250 \mathrm{~K} \\
\mathrm{~T}>1250 \mathrm{~K}\end{array}$ & $\begin{array}{c}4.02810^{-7}+5.46610^{-10} \mathrm{~T}-4.62310^{-13} \mathrm{~T}^{2} \\
3.63710^{-7}\end{array}$ \\
\hline $\begin{array}{c}\text { Young' s modulus, G, } \\
\text { Pa }\end{array}$ & - & $7.1710^{10}$ \\
\hline Poisson's ratio, $v$ & - & 0.16 \\
\hline
\end{tabular}




\section{Mathematical Physics Mode}

The energies equations for the considered physical problem are given as follows:

$$
\nabla\left(K_{p} \nabla T_{p}\right)-\rho C p_{p} \frac{\partial T_{p}}{\partial t}=0
$$

Where, the subscripts 'p' corresponds to the melt, the crystal, the crucible respectively.

The shape of the solid-liquid interface is a compulsory controlling factor that allows producing a single crystal in vertical Bridgman enclosure. This interface shape is predicted by heat transfer and primarily by the direction of the heat flux near the interface.

The thermal stresses problems of anisotropic materials, as semiconductor crystal, in axisymmetric displacement based on thermo-elastic stress model [21] is presented by Fainberg and Leiter [22]. Due to the fact that the gravity is assumed negligible compared with the thermal stress, it is not considered in the equilibrium equations. The governing partial differential equations for momentum balance in an axisymmetric case can be written as:

$$
\begin{aligned}
& 1 \frac{\partial}{\partial r}\left(r \sigma_{\mathrm{rr}}\right)+\frac{\sigma}{\partial \mathrm{z}}\left(\sigma_{\mathrm{rz}}\right)-\frac{{ }^{\theta \theta} \cdots}{\mathrm{r}}=0 \\
& \frac{\partial}{\mathrm{r}}=0 \\
& \frac{\partial}{\partial \mathrm{r}}\left(\mathrm{r} \sigma_{\mathrm{rz}}\right)+\frac{\partial}{\partial \mathrm{z}}\left(\sigma_{\mathrm{rz}}\right)=0
\end{aligned}
$$

Where $\sigma_{\mathrm{rr}}, \sigma_{\mathrm{ZZ}}$ and $\sigma_{\phi \phi}$ are normal stresses in the radial, axial and azimuthal directions, respectively, and $\sigma_{\mathrm{rz}}$ is the shear stress.

The stress-strain relationship of the crystal is taken as [23]:

$$
\sigma_{i j}=C_{i j k l}\left\lceil\varepsilon_{k l}-\beta\left(T-T_{r e f}\right) \delta_{K l}\right\rceil
$$

Where $\sigma_{i j}, \varepsilon_{k l}, \delta_{K l}$ and $C_{i j k l}$ are the stress tensor, strain tensor, Kronecker delta tensor, and elastic constant tensor respectively. $C_{i j k l}$ Takes various forms depending on crystal structure and growth direction.

In the above equation, $\beta=\beta$ is the thermal expansion coefficient. $i j$

The strain-stress relationships are required for the enclosure of the model, and can be denoted by:

$$
\varepsilon_{\mathrm{rr}}=\frac{\partial \mathrm{u}}{\partial \mathrm{r}}, \quad \varepsilon_{\phi \phi}=\frac{\mathrm{u}}{\mathrm{r}}, \quad \varepsilon_{\mathrm{zz}}=\frac{\partial \mathrm{v}}{\partial \mathrm{z}}, \varepsilon_{\mathrm{rz}}=\frac{\partial \mathrm{u}}{\partial \mathrm{z}}+\frac{\partial \mathrm{v}}{\partial \mathrm{r}}
$$

Where $\mathrm{u}$ and $\mathrm{v}$ are displacement components in the radial and axial directions, respectively.

Where $\mathrm{u}$ and $\mathrm{v}$ are displacement components in the radial and axial directions, respectively. Once the stress field has been determined, the Von Mises stress can be determined from the principal stress component and can be a measure of the driving force for dislocation movement [24] and it was used to express the thermal stress in the crystal [25]. It is calculated and defined as:

$$
\sigma_{\text {Mises }}=\sqrt{\frac{\left(\sigma_{\mathrm{rr}}-\sigma_{\mathrm{zz}}\right)^{2}+\left(\sigma_{\theta \theta}-\sigma_{\mathrm{rz}}\right)^{2}+\left(\sigma_{\theta \theta}-\sigma_{\mathrm{zz}}\right)^{2}+6\left(\sigma_{\mathrm{rz}}+\sigma_{\mathrm{r} \theta}+\sigma_{\theta \mathrm{z}}\right)}{2}}
$$




\section{THE BOUNDARY CONDITIONS}

The boundaries conditions corresponding to the temperature field are as follows: the left boundary is kept adiabatic, there is a continuity of thermal condition between the left boundary of the solid state and the ampoule, while the upper, the lower, and the interface position are maintained at $\mathrm{Th}=1400 \mathrm{~K}, \mathrm{Tc}=1200$, and $\mathrm{Tm}=1364 \mathrm{~K}$, respectively.

For the solid domain: The left side, both the radial and axial displacements are axisymetric. For the right side, the axial and the radial displacements are free. For the upper side, the axial and radial displacements are free. For the bottom side, the axial and radial displacements of solid state are fixed.

For the ampoule: for the right, the upper, and the bottom side, the axial and radial displacement are fixed, but the left side of the ampoule, both the radial and the axial displacements are free.

\section{NUMERICAL MODEL}

The numerical approach is developed using COMSOL Multiphysics software, which is based on finite elements method (FEM) with ALE (Arbitrary Lagrangian-Euleurian) formulation.

Many parameters affect the numerical solution since they affect not only the convergence of the problem studied, but also the quality of results. These factors include the choice of mesh quality and the number of mesh used in our study and is given by the Figure 2. The maximum time step $\Delta \mathrm{T}_{\max }=0.01 \mathrm{~s}$, the relative tolerance is $\delta_{\mathrm{r}}=10^{-3}$, and the absolute tolerance is held fixed at $\delta_{\mathrm{a}}=10^{-5}$.The average number of iteration in each time step was 5-10 and the results demonstrate that convergence criterion is reached when the error is less than $10^{-6}$

\section{RESULTS AND DISCUSSION}

Figure.1 demonstrates that the Von Mises stresses is lowered rapidly and undergoes a decreasing trend, for the following parameters, $\mathrm{z}=0.11 \mathrm{~m}, \mathrm{r}=0.016 \mathrm{~m}, \mathrm{Th}=1386$ $\mathrm{K}, \mathrm{Tc}=1320 \mathrm{~K}$ and $\mathrm{Tm}=1364 \mathrm{~K}$. We found that the values of Von Mises decrease from $350 \mathrm{MPa}$ at $\mathrm{t}=5000 \mathrm{~s}, 280 \mathrm{MPa}$ at $\mathrm{t}=25000 \mathrm{~s}, 270 \mathrm{MPa}$ at $36000 \mathrm{~s}$, and $250 \mathrm{MPa}$ at $\mathrm{t}=100000 \mathrm{~s}$. Therefore, to achieve good quality crystals the growth's time must be increased due to the fact that it minimizes the thermal stresses which are sources of contamination of the crystal formation and are the sources of stries and dislocations

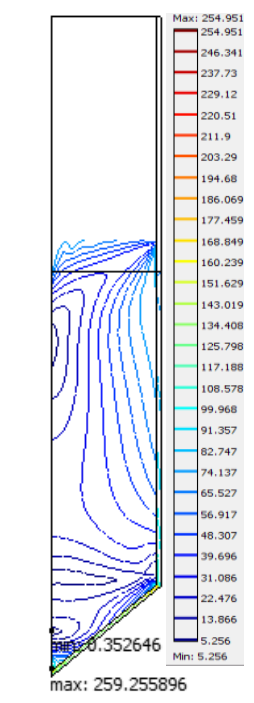

(a)

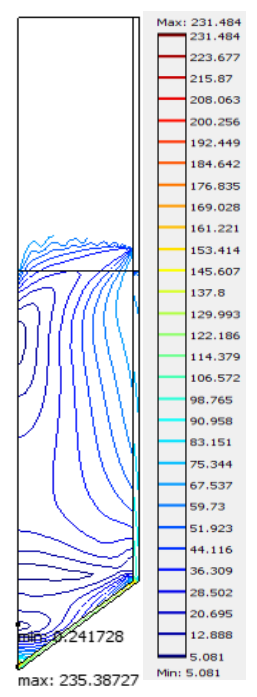

(b)

Figure.1. Profiles of the Von Mises stress for $\mathrm{t}=5000 \mathrm{~s}(\mathrm{a}), \mathrm{t}=100000 \mathrm{~s}(\mathrm{~b}), \mathrm{Tc}=1320 \mathrm{~K}, \mathrm{Th}=1386 \mathrm{~K}$, $\mathrm{Tm}=1364 \mathrm{~K}$, 


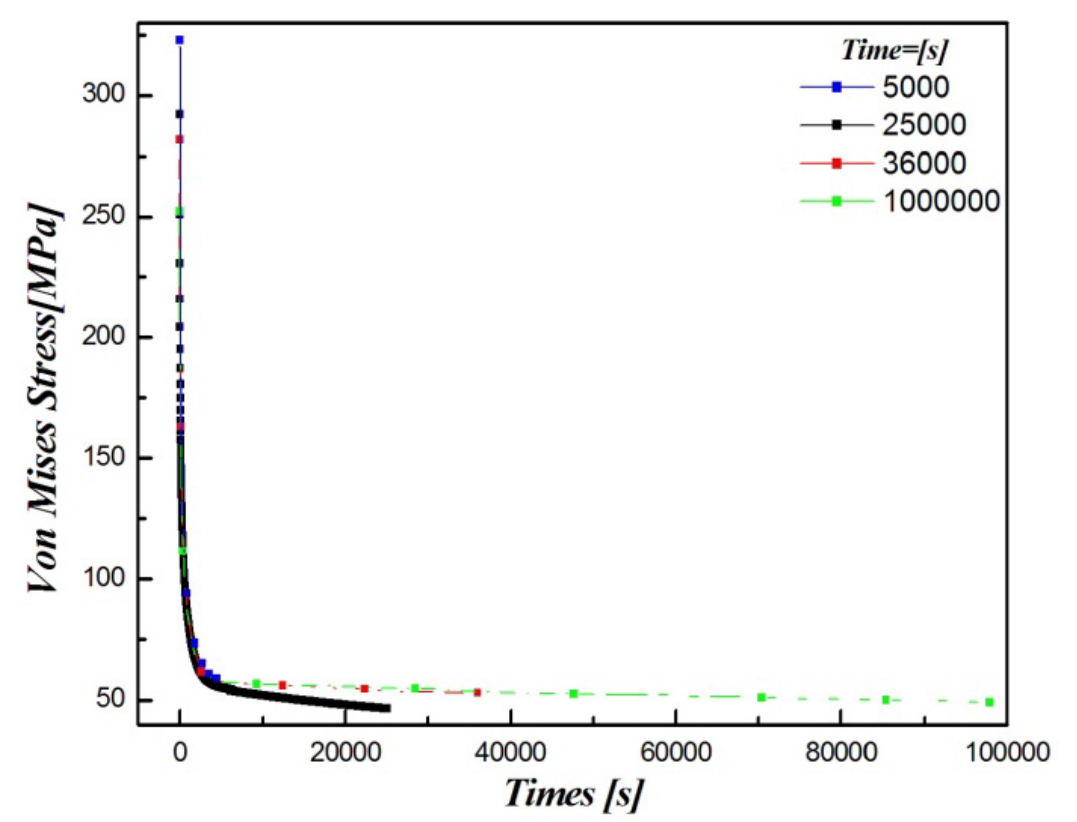

Figure.2. Von Mises profiles for different values of time, at $\mathrm{Tc}=1320 \mathrm{~K}, \mathrm{Th}=1386 \mathrm{~K}, \mathrm{Tm}=1364 \mathrm{~K}$

\section{VISUALIZATION OF THE THERMAL STRESS COMPONENTS}

After studying both parameters that affected the thermal stress, we fixed the values of time growth at $t=100000 \mathrm{~s}$ in which we obtain relatively low thermal stresses localized at the bottom of the solid domain and at the solidification interface. Besides, we fixed the cold temperature at $\mathrm{Tc}=1320 \mathrm{k}$ in which we obtain, not only a minimum thermal stress, but also to keep a concave interface.

In the following study, we present the profiles and the fields of the various components of thermal stress such as the radial stress, angular, axial stress, shear stress and the von Mises Stress.

For this reason, we will see overall the localization and the distribution of thermal stresses throughout the solid state. We noticed from the Figure. 3 (a, b, c, d, e) that the solid state undergoes a compression domain generally at the top of the crystal, but the maximum of thermal stress are located at the bottom of the same crystal, those is shown in Figure.3 (a, b, c, e) except the figure.3 (d) in which, we noted that the shear stress is shown on the edge of the solid area and the crucible.

To better understand what is actually happening in the solid domain, we will present the radial and the axial profiles of the various components of the thermal stress. 

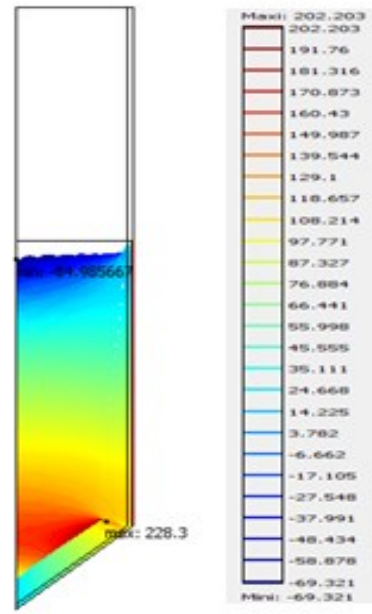

(a)

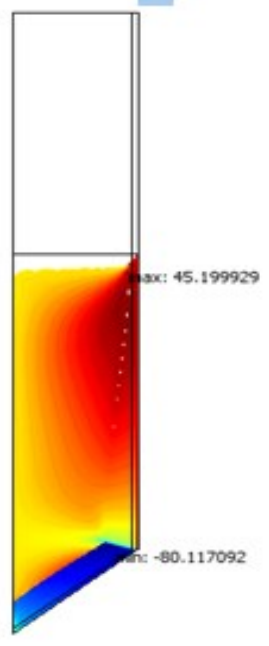

(d)

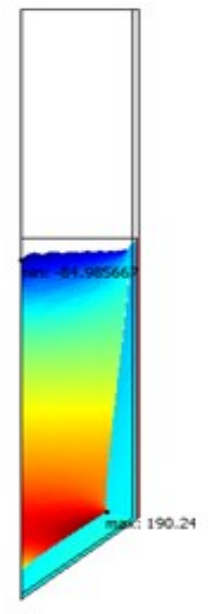

(b)
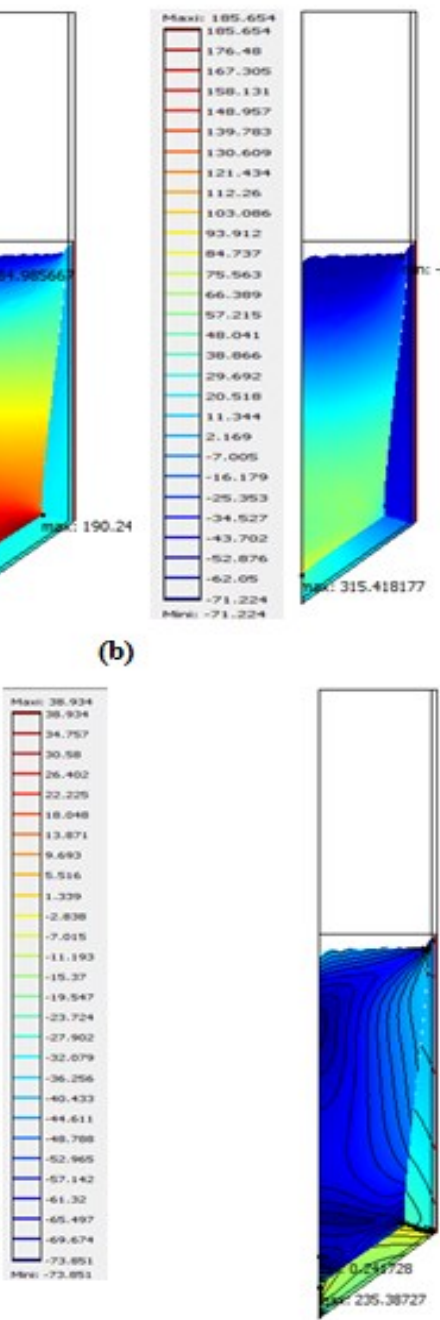

(e) (c)
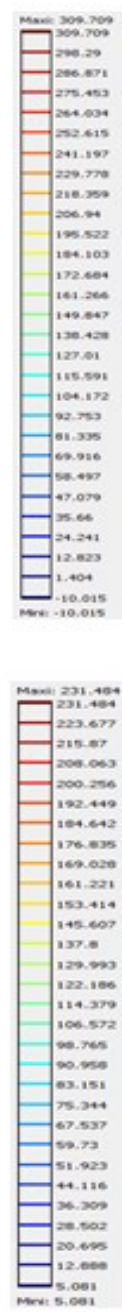

Figure.3Thermal stress fields, $\sigma_{\mathrm{rr}} \mathrm{MPa}(\mathrm{a}), \sigma_{\theta \theta} \mathrm{MPa}(\mathrm{b}), \sigma_{\mathrm{ZZ}} \mathrm{MPa}(\mathrm{c}), \sigma_{\mathrm{rZ}} \mathrm{MPa}(\mathrm{d}), \sigma_{\mathrm{Mises}} \mathrm{MPa}(\mathrm{e})$

\section{VISUALIZATION OF THE RADIAL STRESS}

Figure.3 (a) shows that the solid phase is compressed at the bottom of the crystal, and the solid was moved parallel to the lower limit of the solid domain, and the thermal stress is about 228 $\mathrm{MPa}$. This value follows the compression of the solid domain, it is maximum at the bottom of the solid domain. During this, we also note the presence of a strengthened zone near the solid area which undergoes a compression.

Figure.4 (a, b) illustrates the profiles of radial stress for radial and axial positions respectively. In fact, The Figure.4 (a) shows that the maximum radial stress is located at the bottom of the crystal, this value reaches a maximum near the right wall of the solid domain. Then, it decreases inside the crucible, but by always keeping high values compared to the values of the radial stress measured for $\mathrm{z}=0.05 \mathrm{~m}$, where we noted that the profile is almost constant. Meanwhile, the values of the radial stress are negative at the interface of solidification, which shows that the solid is subjected to compression.

The variation of thermal stress with axial coordinates for different radius $r$ is given by the Figure. 4 (b), in which we proved that the values reach their maximum at the bottom of the crystal $(200 \mathrm{MPa})$ for $\mathrm{r}=0.016 \mathrm{~m}$. After that, they are subjected equal to $(-50 \mathrm{MPa})$ in the bottom of crystal, which corresponds to compression of the solid area. But if we are approaching to the right vertical wall of the solid domain, we note that the radial stresses reach their maximums for $\mathrm{r}=0.037 \mathrm{~m}$, but this value is dropped while approaching the interface. 
We noted then, that for $r=0.039$ which present the inner wall of the crucible, that the stress is important proving that the crucible is the one of most important factor to creating stress.

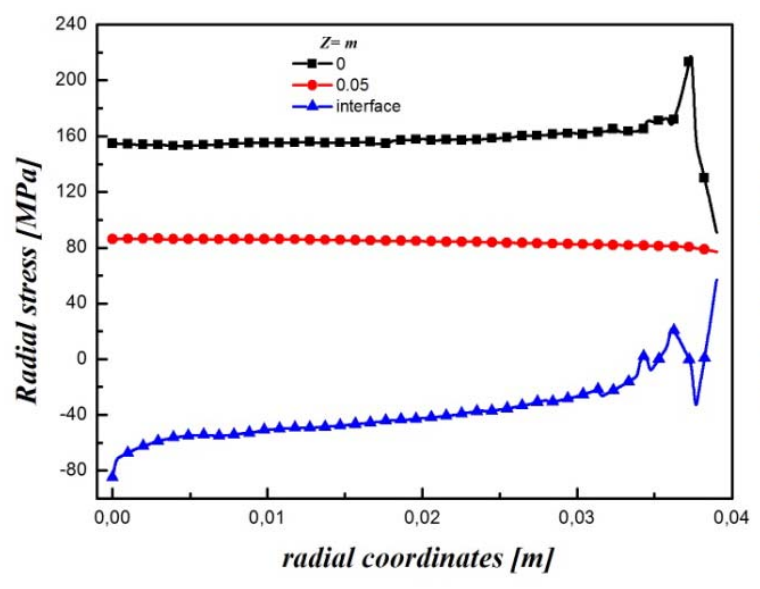

(a)

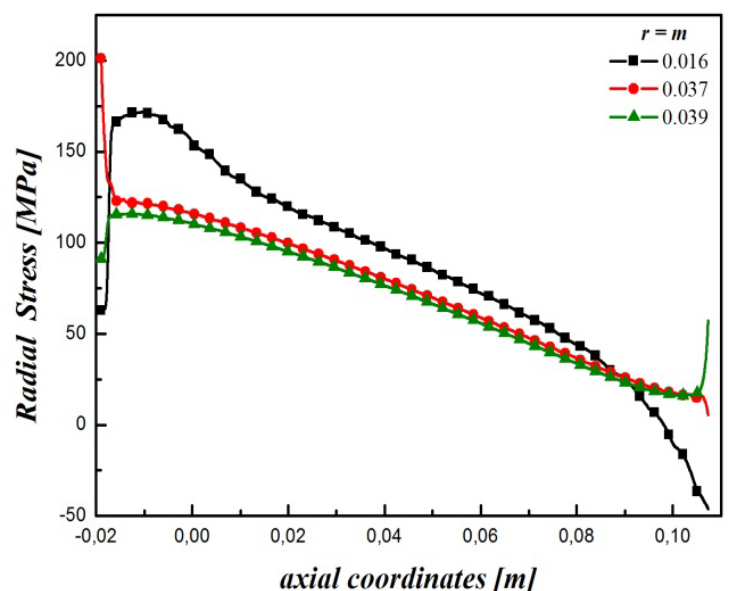

(b)

Figure.4. The profiles of $\sigma_{\mathrm{rr}}$ for radial (a) and axial coordinates (b) at at $\mathrm{Tc}=1320 \mathrm{~K}, \mathrm{Th}=1386 \mathrm{~K}$,

$\mathrm{Tm}=1364 \mathrm{~K}$ and $\mathrm{T}=100000 \mathrm{~s}$

\section{VISUALIZATION ANGULAR STRESSES}

Figure.3 (b) shows the angular thermal field, where it is noted that the entire solid domain undergoes compression and are on the edge of the right wall of solid field. This compression can be seen clearly from Figure. 5 (b) illustrating the variation of $\sigma \theta \theta$ as a function of axial coordinates for different values of $r$ taken where stresses exhibit a drop from (175 $\mathrm{MPa})$ to $(-50 \mathrm{MPa})$ for $r=0.037 \mathrm{~m}$. In fact, we can see that for this chosen value of $r$, the stress decreases to a negative value, this decrease is due to the edges of the ingot that cools quickly releasing heat by conduction. Thus, the edge of the rod solidified will play the role of a mature preventing the core, which has not yet reached the same temperature, to dilate.

On the other hand, Figure. 5 (a) depicts the angular radial thermal profiles for different values of $z$ taken, where it is noted that the latter decreases away from the bottom of the crystal as they reach their maximum values for $\mathrm{z}=0 \mathrm{~m}$. By approaching the interface solidification, angular stresses decrease and become negative due to the compression of the solid area.

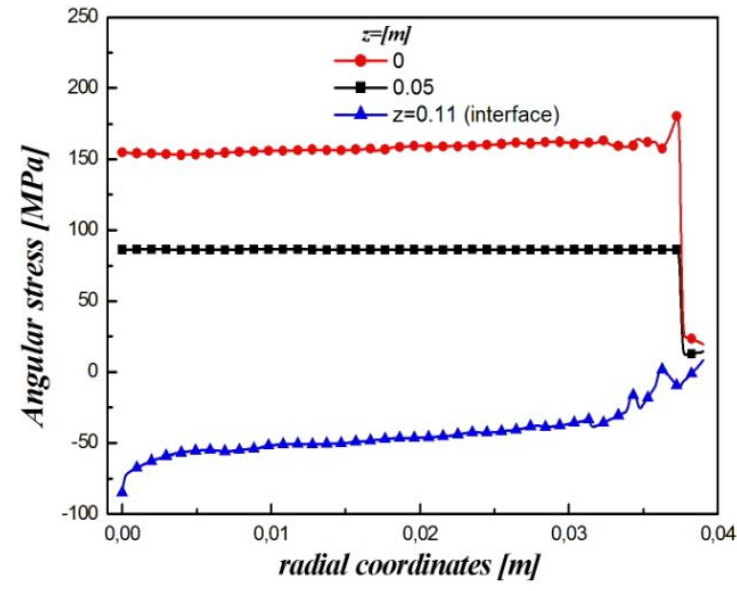

(a)

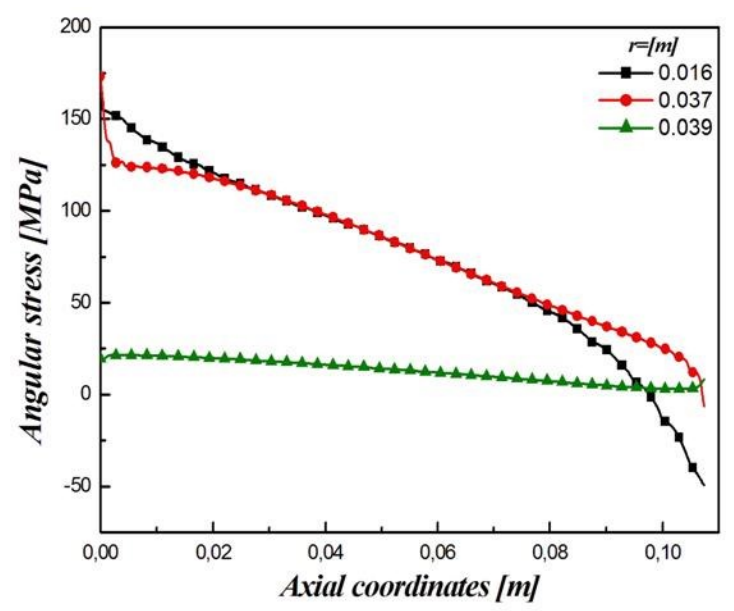

(b)

Figure.5. The profiles of $\sigma_{\theta \theta}$ for radial (a) and axial coordinates (b) at at $\mathrm{Tc}=1320 \mathrm{~K}, \mathrm{Th}=1386 \mathrm{~K}$, $\mathrm{Tm}=1364 \mathrm{~K}$ and $\mathrm{T}=100000 \mathrm{~s}$ 


\section{VISUALIZATION OF THE AXIAL STRESS}

For the visualization of the axial stress field $\sigma_{z z}$ given by Figure.3(c), we note that it keeps the same profile as the angular thermal field but the values of the axial thermal stresses are highest at the bottom. This was also noticed by studying the axial thermal stress profiles based on the radial and axial coordinates for different positions of $\mathrm{r}$ and $\mathrm{z}$, respectively, (Figure 6 (a, b )) . Note that these thermal stresses are lowered from the solidification interface and reach a very important value in approaching the bottom of the crystal Figure.6 (a). From the same figure we may also observe that the axial thermal stress undergoes a dropping trend by approaching the bulb containing the solid domain. However, this value is too high, which proves that it plays an important role in the formation of large defects and scratches during crystal growth.

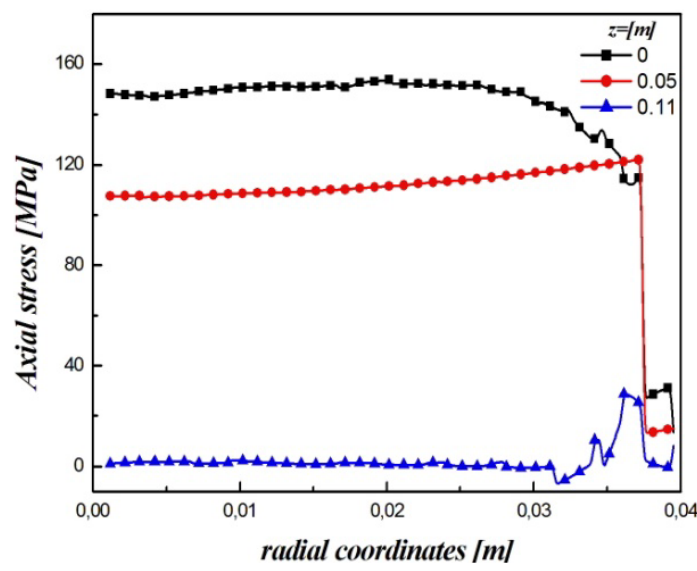

(a)

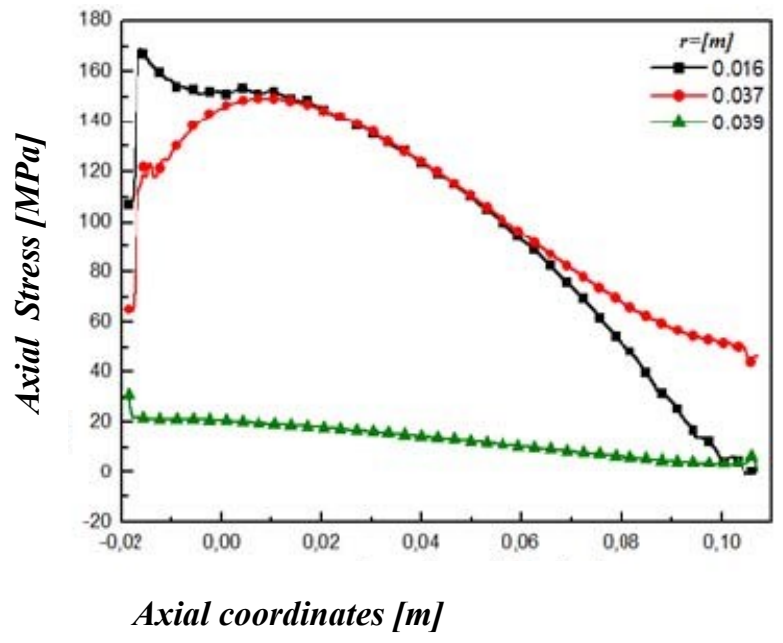

(b)

Figure.6. The profiles of $\sigma_{\mathrm{ZZ}}$ for radial (a) and axial coordinates (b), at $\mathrm{Tc}=1320 \mathrm{~K}, \mathrm{Th}=1386 \mathrm{~K}$, $\mathrm{Tm}=1364 \mathrm{~K}$ and $\mathrm{T}=100000 \mathrm{~s}$

\section{VISUALIZATION OF THE SHEAR STRESS}

The Figure.3(d) gives an overview on the distribution of shear stress, where the presence of two zones tightening of contours can be seen; one is located at the bottom area of the solid value nearly equal to ( -60$) \mathrm{MPa}$, the stress is compressive . Quantitatively, this zone is seen to be weak compared to that which is located on the edge of the vertical wall of solid zone just above the solidification front, which is the maximum value of $45 \mathrm{MPa}$. In addition, it reflects the effect of gradients thermal intense near the interface of the lingo, subjected to flow exerted by the crucible. This proves that the bottom of the lingo is in compression while the upper zone is dilated.

Figure.7 (a) shows the profile of the longitudinal shear stress. However, we can reveal that this longitudinal stress is important at the bottom of the solid area for $z=(-0.01 \mathrm{~m})$, where the solid domain will undergo compression. This value increases, reaching a maximum value close to (-40) MPa proving compression of the crystal. By approaching the solidification interface, the shear stresses become almost zero, but they become important near the upper vertical wall of solid area where we see the location of shear pre solid field and approaching the bulb which proves the negative effect of the bulb on the formation of shear stresses.

Figure.7(b) describes the variation of the transverse shear stress for various positions $r$. This demonstrates that the shear stresses become large by increasing the radius of the lingo solidification exactly on the inner end of the sound field at $r=0037 \mathrm{~m}$ and towards the vertical wall of the ampoule at $\mathrm{r}=0.039 \mathrm{~m}$. 


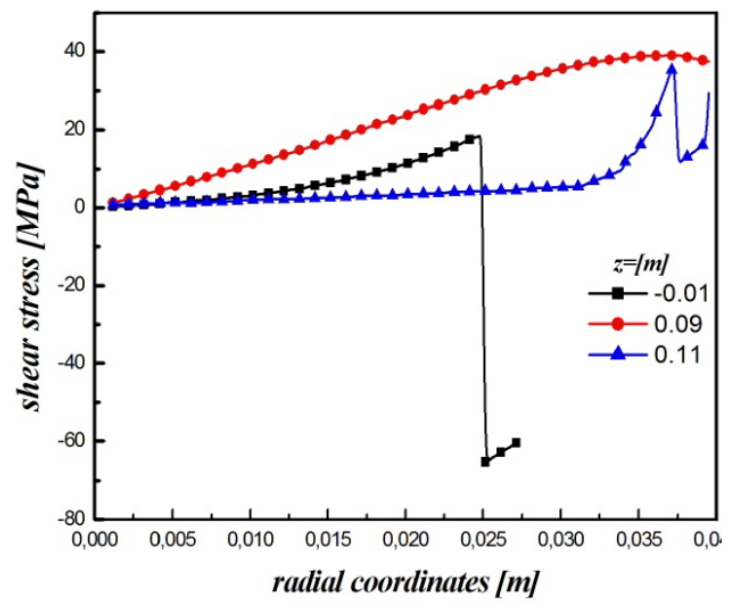

(a)

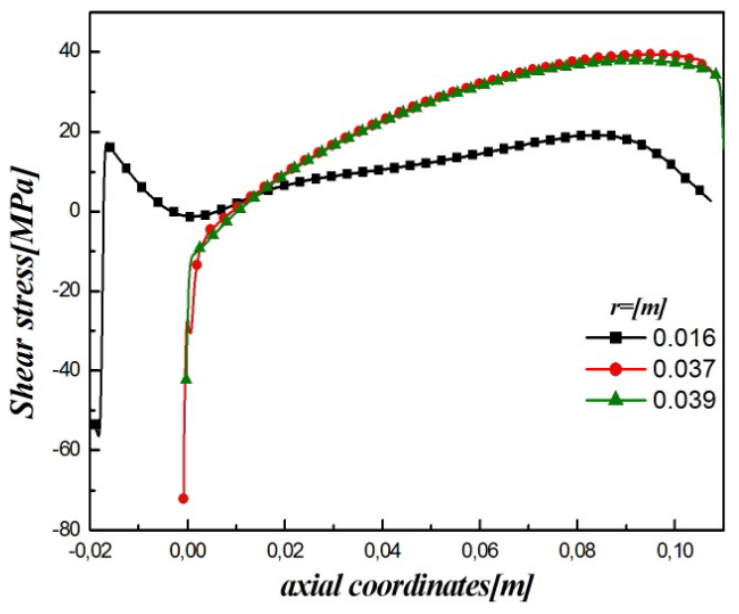

(b)

Figure. 7. The profiles of shear stress $\sigma_{\mathrm{rZ}}$ for radial (a) and axial coordinates (b) at at $\mathrm{Tc}=1320 \mathrm{~K}$, $\mathrm{Th}=1386 \mathrm{~K}, \mathrm{Tm}=1364 \mathrm{~K}$ and $\mathrm{T}=100000 \mathrm{~s}$

\section{VISUALIZATION OF THE VON MISES STRESS}

The Figure.3 (e) and the Figure.8(a, b) illustrate the field distribution of the Von Mises stress and the longitudinal and transverse profiles of CdZnTe lingo. In fact, at the first figure we can see that the field of the Von Mises stress confirms what has been shown in other fields for other components of the thermal stress, where the maximum of these constraints is located at the bottom of crystal, with an exception that appears in the presence of another outstanding high meadows tightening the left vertical wall of the solid domain, and that goes to the other vertical wall above the interface, proving the importance of gradient heat.

The Figure.8 (a) depicts the longitudinal variation of the Von Mises stress for different axial positions z. It is noticed that it proves the same pattern reflected by Figure .10 (e) which is observed for $z=(-0.01) \mathrm{m}$ demonstrating that these stresses are located at the bottom of the crystal while they decrease for $\mathrm{z}=0.05 \mathrm{~m}$ and $\mathrm{z}=0.08 \mathrm{~m}$. However, we note that on the Von Mises solidification interface at $\mathrm{z}=0.11 \mathrm{~m}$ are also important, though decrease reaching a minimum of $20 \mathrm{MPa}$, and then they go back again near the solid area, $\mathrm{r}=0.037 \mathrm{~m}$ and near the interface of the inner bulb, for $r=0.039 \mathrm{~m}$, demonstrating the detrimental effect of the impact of the contact between the solid area and the bulb taking place where the material growth CdZnTe .

The Figure.8 (b) shows the cross-sectional variation of the Von Mises stress for different radial positions $\mathrm{r}$. We note the particular shape taken by these curves. They form a $\mathrm{W}$-like collects found by Benmeddour [30], and Volk et al [31] in their studies of the thermal stresses in Silicon crystals. Similarly, we note that the profile of the Von Mises stress as a function of $\mathrm{z}$, decreases and is dropped for different radial positions $r=r=0.016 \mathrm{~m}$ and $0.037 \mathrm{~m}$, and that even approaching the bulb where the solidification takes place, the change is also important that stress 


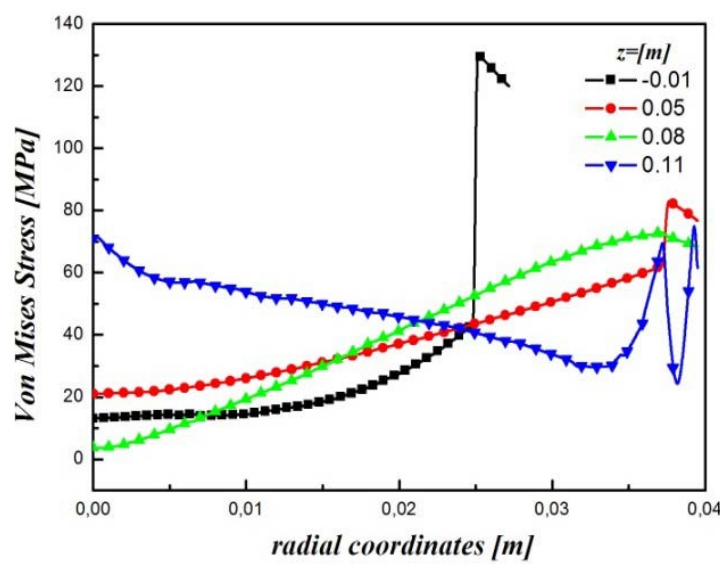

(a)

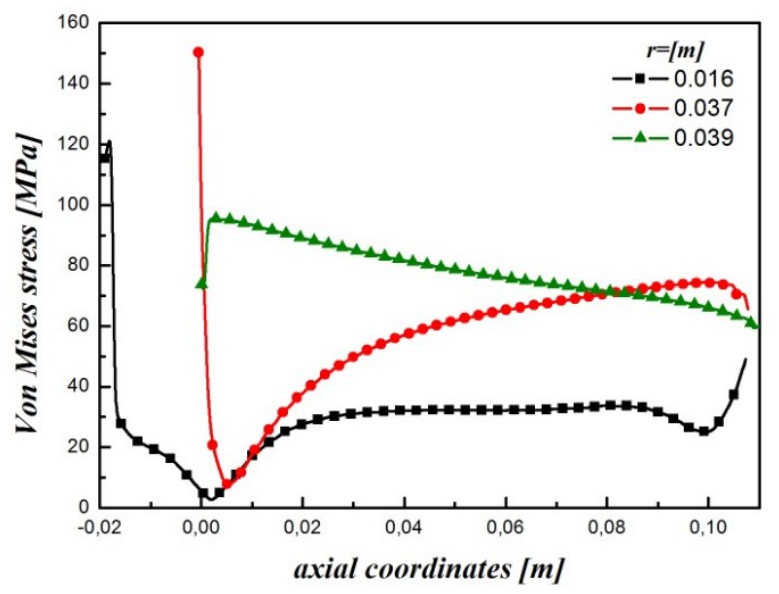

(b)

Figure.15. The profiles of Von Mises stress for radial (a) and axial coordinates (b) at at $\mathrm{Tc}=1320 \mathrm{~K}$, $\mathrm{Th}=1386 \mathrm{~K}, \mathrm{Tm}=1364 \mathrm{~K}$ and $\mathrm{T}=100000 \mathrm{~s}$

\section{CONCLUSION}

This numerical modeling investigation aims to conduct a detailed and explanatory study of thermal stress and its components in the process of solidification of CdZnTe in Bridgman configuration vertical. These stresses are the consequences of the thermal gradient, which influences the shape final crystal and consequently its quality. It presented the effect of temperature on the cold thermal stress, where it was observed that increasing the temperature decreases the thermal stress. This allows choosing the appropriate temperature which permits the same time a concave interface (with minimum thermal stresses) and a minimum of thermal stresses.

The time increased growth also aims to minimize the thermal stress to which allows us to determine the time $\mathrm{t}=100000 \mathrm{~s}$

\section{References}

[1] R.B James, P Siffert, Eds. 11th International Workshop on Room Temperature Semiconductors and Associated Electronics. Nucl. Instrum.Methods Phys. Res. A 2001, 458, $1-603$.

[2] Phlips, B., Ed. 15th International Workshop on Room-Temperature Semiconductor X- and Gamma-Ray Detectors. IEEE Nucl. Sci. Symp.Conf. Rec. 2006, 6, 3585-393

[3] P.Z.Gao, S.L.Liu, W.K Chow, N.K.Fong, Large eddy simulation for studying tunnel smoke ventilation, Tunneling and underground Technology. 2004; 19, pp 577-586.

[4] K.S.Doan, M.Stage, J.Coutanceau, Transferts de chaleur entre un fil anémométrique court et un écoulement permanent à faible vitesse, Rev.Gén.Therm. 1975; 168, 951-956.

[5] K.S.Doan, M.Stage, J.Coutanceau, Transferts de chaleur entre un fil anémométrique court et un écoulement permanent à faible vitesse, Rev.Gén.Therm. 1975; 168, 951-956.

[6] Abbene, L.; La Manna, A.; Fauci, F.; Gerardi, G.; Stumbo, S.; Raso, G. X-ray spectroscopy and dosimetry with a portable CdTe device. Nucl. Instrum. Methods Phys. Res. A 2007, 571, 373- 377. [7] Miyajima, S.; Imagawa, K.; Matsumoto, M. CdZnTe detector in diagnostic xray spectroscopy. Med. Phys. 2002, 29, 1421-1429.

[8] Miyajima, S. Thin CdTe detector in diagnostic x-ray spectroscopy. Med. Phys. 2003, 30, 771-777. 
[9] Bottigli, U.; Golosio, B.; Masala, G.L.; Oliva, P.; Stumbo, S.; Delogu, P.; Fantacci, M.E.; Abbene, L.; Fauci, F.; Raso, G. Comparison of two portable solid state detectors with an improved collimation and alignment device for mammographic x-ray spectroscopy. Med. Phys. 2006, 33, 3469-3477.

[10] Fang H.S, Wanga S., Zhou L, Zhou N.G, Lin M.H , Influence of furnace design non the thermal stress during directional solidification of multicrystalline silicon, Journal of Crystal Growth 346 (2012)5-11.

[11] Huang C. E, Elwell D, and Feigelson R. S, J. Journal of Crystal Growth 69 (1984) 275. [12] Huang C. E, Elwell D, and Feigelson R. S, J. Journal of Crystal Growth 64 (1984) 441

[13] C.K. Chao, S.Y. Hung, Stress analysis in the vertical Bridgman growth with the modified thermal boundary condition, Journal of Crystal Growth 256 (2003) 107-115

[14] W. Rosch, F. Carlson, J. Crystal Growth 109 (1991) 75.

[15 H.S. Fang, S.Wang, L. Zhou, N. G. Zhou, M.H. Lin, Influence of furnace design on thermal stress during directional solidification of multicristalline silicon, J. Crystal Growth 346 5-11 (2012).

[16] J.J. Derby, D. Gasperino, Computational models for crystal growth of radiation detector materials: growth of CZT by the EDG method, in: D. Perry, A. Burger, L. Franks, M. Schieber (Eds.), Nuclear Radiation Detection Materials, Materials Research Society Symposium Proceedings, vol. 1038, 2008, pp. 1038-005-09

[17] A. Datta, K. Jones, S. Swain, K. Lynn, Modified vertical Bridgman growth of Cd1-xZnxTe detector grade crystal in a 4 inch EDG furnace, in: Nuclear Science Symposium Conference Record (NSS/MIC), 2009 IEEE, 2009, pp. 1771-1776.

[18] D.J. Gasperino, Modeling of Transport Processes during Solution, Melt and Colloidal Crystal Growth, Ph.D. Thesis, University of Minnesota, 2008.

[19] Parfeniuk C., F. Weinberg and I. V. Samarasekera, J. Crys. Growth 119, 261 (1992). [20] L. Juncheng, Science in China Ser. E 47, 725 (2004).

[21] Marchenko Marina, P., Vladimir, D., Golyshev , Bykova Svetlana, V. , Investigation of Cd1-xZnxTe composition inhomogeneity at crystal growth by AHP-method, Journal of Crystal Growth 303 (2007) 193-198

[22] Fainberg J, Leister H.J, Comput. Methods Appl. Mech. Eng.137 (2) (1996) 167.

[23] Fang H.S, Wang S, Zhou L, Zhou N.G, Lin M.H, Influence of furnace design on the thermal stress during directional solidification of multicrystalline silicon, Journal of Crystal Growth 346 (2012) 5- 11

[24] Chao C. K, Hung S.Y, Stress analysis in the vertical Bridgman growth with the modified thermal boundary condition, Journal of Crystal Growth 256 (2003) 107-115.

[25] Juncheng Liu and Guodong Zhang, Numerical Simulation of the Thermal Stress Field during Vertical, Journal of the Korean Physical Society, Vol. 53, No. 5, November 2008, pp. 2989-2995.

[26] C. Cerny, A. Kalbac, P. Prikryl, Computational modeling of CdZnTe crystal growth from the melt, Computational Materials Science 1734-60(2000)

[27] N. Zhang, A. Yeckel, J. J.Derby, Maintaining convex interface shapes during electrodynamic gradient freeze growth of cadmium zinc telluride using a dynamic, bellcurve furnace profile, J. Cryst. Growth 355 113-121 (2012) 
[28] Juncheng liu and Guodong Zhang (2008): Numerical simulation of the thermal stress field during vertical Bridgman CdZnTe single crystal growth, Journal of the Korean Physical Society, Vol. 53, No. 5, pp. 29892995

[29] A. Shimizu, J. I. Nishizawa, Y. Oyama and K. Suto (2002) , J Cryst Growth 237-239, 1697

[30] Ben meddour Amor (2010): Etude et simulation numériques des contraintes thermomécaniques dans le silicium photovoltaïque. Thèse pour obtenir le grade de Docteur en Sciences spécialité « Génie Mécanique »

[31] J. Volk1, G. Muller (1989):A new model for the calculation of dislocation formation in semiconductor melt growth by taking into account the dynamics of plastic deformation, J. Crystal Growth 97 136-145. 